\title{
DIABETES
}

AMPUTATION RATES

\section{FALL IN FINLAND}

A decreased incidence in first major lower limb amputation was found in both the diabetic and nondiabetic population between 1997 and 2007, according to the findings of a Finnish populationbased study. In the diabetic population this decrease was almost $50 \%$.

The incidence of diabetes mellitus in Finland is increasing rapidly. The National Development Programme for the Prevention and Care of Diabetes (DEHKO) aims to reduce the complications of diabetes mellitus in Finland, a key goal being to halve the incidence of lower limb amputations. Ikonen's research team consequently set out to evaluate the effect of the DEHKO program on national amputation rates.

Individuals with diabetes mellitus

( $n=396,317)$ were identified from comprehensive Finnish health registers. Standardized incidence of first major lower limb amputations was reduced by $48.8 \%$ in the diabetic population and $25.2 \%$ in the nondiabetic population. The period between diabetes diagnosis and first major amputation increased by an average of 1.2 years.

The reduction in the incidence of the first major amputation reflects results elsewhere in Europe. In the diabetic cohort, this decrease was attributed to improved diabetic care via better podiatry and enhanced coordination with vascular and plastic surgery treatments.

Post-amputation 5-year mortality among patients with diabetes mellitus remained high (78.7\%), possibly reflecting the aggressive policy of amputation in individuals for whom limb salvage was unlikely to be successful or in cases of low life expectancy. Ikonen concludes that "earlier diagnosis, careful blood sugar control, improved foot care and vascular services will have a positive impact on diabetic limb salvage." The research team plan to investigate further into regional and socioeconomic effects on lower limb amputations.

Rosanne Diaz

Original article lkonen, T. S. et al. Fewer major amputations among persons with diabetes in Finland in 1997-2007-a population-based study. Diabetes Care doi:10.2337/dc10-0462 